\title{
DEVELOPING A PREDICTIVE MODEL OF SUBJECTIVE ORGANISATIONAL CULTURE
}

\author{
ANNALIE STRYDOM \\ GERT ROODT \\ gr@rau.ac.za \\ Department of Human Resource Management, \\ University of Johannesburg
}

\begin{abstract}
The objective of this theory development study was to propose a predictive model of subjectively perceived organisational culture with biographic variables, job satisfaction and personality variables as predictors. A countrywide sample of convenience drawn from a population of nurses $(\mathrm{N}=3456)$ of a private healthcare service provider in South Africa yielded 713 completed questionnaires (response rate $=21 \%$ ) that were obtained in multiple sessions. Goal directedness, a dimension of organisational culture, was significantly positively related to all three measures of satisfaction (imposed personal demands, extrinsic satisfaction and intrinsic satisfaction), while internal climate was significantly negatively related to the three satisfaction dimensions. Other significant findings are reported on.
\end{abstract}

Key words

Subjective organisational culture, job satisfaction, personality, sense of coherence, self-efficacy

The current study was conducted among nurses of a private healthcare service provider operating 42 hospitals and employing about 12000 people. The healthcare industry is characterised by excessive nurse turnover and/or brain drain seemingly stimulated by issues related to poor conditions of service and/or remuneration. The current study will therefore explore a number of proposed predictors in order to determine whether subjectively perceived organisational culture is predominantly the function of contextual or dispositional factors. Payne and Pugh (1983) made the distinction between subjective and objective measures of organisational climate.

Successful organisations meet the needs and expectations of their customers more effectively than their competitors; at the same time, they generate acceptable financial returns. According to Thompson (2001) to achieve these outcomes, committed and competent people are required. According to Thompson (2001) successful companies will be able to attract, motivate, develop, reward and keep skilled and competent managers and other employees. The constant heavy losses of recruited neophytes and qualified nurses from the profession constitute one of the biggest headaches in the healthcare industry (Booyens, 1993). She mentioned that it is a laborious and time-consuming task to recruit sufficient nurses to the profession, and the retention of staff is even more difficult. It therefore seems to be a problem to achieve acceptable outcomes if nurses are not committed to stay in a particular company.

For a number of years, one of the concerns confronting the nursing profession at national and international levels has been a shortage of qualified nurses. According to Calhoun (2002) nursing is facing significant challenges in many countries. In the United States, the rising shortage of nurses has reached crisis proportions, affecting the quality of patient care. This has resulted in the unnecessary loss of life, inappropriate care, unnecessarily extended hospitalisation and additional costs of care. Therefore, it seems important to hold on to valued and skilled employees or to recruit the right people for the job, in order to deliver and render superior health care to the nation. One would not like to see that health organisations have to close down because of the nursing shortage experienced in the health industry nationally and internationally. In this regard it seems necessary to explore a wider variety of factors that may impact on a nurse's decision to leave a particular company. These may include personality variables and organisational culture.

A healthy work environment provides a grounded structure with policies, procedures, and systems that allow employees to achieve personal and organisational goals versus an unhealthy work environment fraught with stress, hostility and authoritarianism (Disch, 2000). The work environment is seen as a variable that influences job satisfaction and as a reason why nurses remain in or leave a position of employment (Cooper, Frank, Gouty \& Hansen, 2002). It seems that in the past, job satisfaction has often been associated with situational variables. Judge, Locke, Durhan and Kluger (1998) believed that factors within the individual (dispositional factors), rather than merely the context (characteristics of the situation), affect an individual's job satisfaction. It is therefore also a secondary objective of this study to determine whether personality variables mediate the relationship between job satisfaction and subjectively perceived organisational culture.

\section{Job satisfaction and organisational culture}

Job satisfaction in professional nurses should be of great concern to any health organisation. When professional nurses leave the profession or place of work, some degree of job dissatisfaction is implied. Nurses hold the majority of positions in most healthcare settings, and the replacement of professional nurses is costly and time consuming. Certain hospitals possess organisational characteristics that allow nurses to use their expertise, knowledge and skills to provide quality care. These organisations have been able to weather national nursing shortages because of their favourable reputation for attracting and retaining nurses (Sullivan-Havens \& Aiken, 1999). Irvine and Evans (1995) reported that nurses who have shown higher levels of job satisfaction report a greater likelihood of remaining in their current institution. Considering the impact of the current critical nursing shortage, very little research was found on whether hospitals are able to provide increased job satisfaction among clinical nurses in today's healthcare setting.

Coetzee (1999) conducted research in South Africa and the purpose of his study was to determine the relationship between organisational culture and job satisfaction to establish what the dominant culture of each factory was, and to establish whether the workers experienced job satisfaction or dissatisfaction. There were no significant statistical correlations between organisational culture and the specific job satisfaction dimensions where the three factories used in this study were characterised by a dominant power-driven organisational culture. In all three factories, job dissatisfaction was experienced and a Pearson's Product moment correlation showed that there was a significant statistical relationship between organisational culture and job satisfaction. ANOVA and MANOVA procedures indicated significant statistical differences between job satisfaction scores and organisational culture scores. 
Sempane, Rieger and Roodt (2002) conducted a study to establish whether, among employees in a service organisation, a relationship existed between the variables job satisfaction and organisational culture. In their research, a significant positive correlation between the two variables $(r=0,743)$ was found. In a study conducted by Tzeng, Ketefian and Redman (2002), the aim was to determine the relationship between nursing care and nurses' assessment of organisational culture, job satisfaction and patient satisfaction. Tzeng et al. found that organisational culture positively predicted job satisfaction.

The first two of the abovementioned studies used relatively small sample sizes. Therefore, it would be difficult to generalise a relationship between job satisfaction and organisational culture. Although the last study had a relatively large sample, Tzeng et al. (2002) selected staff nurses. Staff nurses are of a lower category than professional nurses and the nursing shortage does not include this category. Therefore, the present study was conducted to target the professional nurses who are not easily replaced and retained.

Personality, job satisfaction and organisational culture Argyris (1972;1957) argued that the proper development of an individual requires the consideration of both the nature of the personality and the nature of the context in which the person behaves. Flowing from this argument is a general proposition that many of the 'human problems' in organisations can be attributed to the basic incongruence or lack of fit between the nature of relatively mature individuals - in so far as 'relative maturity' is reflected in personality - and healthy formal organisations. The ' $\mathrm{fit}$ ' or 'congruence' proposition between organisation and individual is not a new one, but was also proposed by Lawrence and Lorsch (1967) and later by Nadler and Tushman (1986). These theoretical premises provide the theoretical context for investigating the relationship between personality and subjectively perceived organisational culture.

The personalities and general attributes of nursing personnel are considered to be of great importance for their interactions with patients and these may influence work satisfaction (Sand, 2003). Sand further stated that nursing requires calmness of mind, being completely present in the situation and devoting complete attention to patients. At the same time, nursing care can cause feelings of discomfort. This underscores the importance to consider certain personality variables and their relationship with job satisfaction and organisational culture.

Research was conducted to investigate the effect of personality determinants versus organisational factors on job attitudes, especially job satisfaction (Gerhardt, 1987; Staw \& Ross, 1985). Some of the findings were that previous job satisfaction seemed to be a significant indicator of current job satisfaction, rather than salary and job complexity. Furthermore, personality dispositions (as opposed to a learnt behaviour) influence job satisfaction more decisively than organisational factors. Miller, Griffin, Hart and Hart (1999) investigated the contribution of conscientiousness to organisational health. Organisational health research identifies processes through which the work environment and individual differences combine to influence both individual and organisational outcomes. Within this framework, the work environment was assessed in terms of perceptions of workload and role clarity; individual well-being was assessed in terms of psychological distress and job satisfaction; and behaviour important for organisational success was assessed in terms of contextual performance. Conscientiousness directly influenced contextual performance but did not influence well-being or perceptions of the work environment. Conscientiousness also reduced the impact of role clarity on both psychological distress and job satisfaction.

In two studies Furnham, Petrides, Jackson and Cotter (2001) investigated the relationship between personality traits and aspects of job satisfaction. In both studies personality traits accounted for a small percentage of the total variance - both in importance ratings and in levels of job satisfaction. They concluded that personality does not have a strong or consistent influence on what individuals perceive as important in their work environment or on their levels of job satisfaction. Tokar and Subich (1997) as well as Brief, Butcher and Roberson (1995) found that extraverts and neurotics are respectively more and less likely to report job satisfaction. In a study conducted by Rothmann and Coetzer (2002), the relationship between personality dimensions and job satisfaction was determined in a pharmaceutical organisation. The results showed that job satisfaction has a negative relationship with Anger-hostility (component of Neuroticism), whereas it has a positive relationship with positive emotions (a facet of Extraversion), confidence, altruism and compliance (facets of Agreeableness) as well as facets of Conscientiousness. Personality dimensions explained $28 \%$ of the variance of job satisfaction.

Organ and Andreas (1995) hypothesised that the personality dimensions, agreeableness and conscientiousness, account for a commonly shared variance between job satisfaction and organisational citizenship behaviour (OCB). The findings, obtained from 99 employees in the UK and US, indicated that these two dimensions indeed accounted for substantial variance in satisfaction, and that conscientiousness also accounted for unique variance in one dimension of OCB. Satisfaction accounted for unique variance in OCB not explained by either of these personality dimensions. In a study conducted by Ilies and Judge (2002), the within-individual relationship between mood and job satisfaction was investigated and the role of personality characteristics in moderating this relationship was examined. They found, firstly, that within-individual variance comprised $36 \%$ of the total variance in job satisfaction, and mood explained $29 \%$ of the within-individual variance in job satisfaction. Secondly, both mood and job satisfaction were related within and across individuals. Thirdly, two personality traits Neuroticism and Extraversion - were associated with average levels of mood. Fourthly, within-individual variability in mood was significantly related to within-individual variability in job satisfaction, and variability in both mood and job satisfaction was predicted by Neuroticism. Finally, personality impacted on the degree of association between mood and job satisfaction within individuals.

Although the research cited above was conducted on job satisfaction and personality dimensions, it was found that either small sample groups have been used or that insufficiently consistent findings were available to generalise the findings. No specific research was found in the nursing field or health industry on the so-called "Big Five" personality dimensions and the relationship between job satisfaction and organisational culture.

\section{Sense of coherence, job satisfaction and}

\section{organisational culture}

Nursing can be experienced as a stressful job and therefore it would be important to measure the way in which nurses appraise the world and how they cope with the cognitive and emotional stress associated with the job. In three separate studies using different samples, Strümpfer and Mlonzi (2001) investigated sense of coherence's relationship to job satisfaction, job involvement, organisational commitment and conscientiousness. In their study with insurance consultants, significant relations between sense of coherence with job satisfaction and commitment were revealed, but not with job involvement. In their study with working adults, significant relations between sense of coherence and job satisfaction, commitment and conscientiousness were found. In their study with university teachers, the job satisfaction relations were of practical significance, explaining $15-35 \%$ common variance in sense of coherence. Small sample groups were used so it is rather difficult to generalise the findings. A study by Levert, Lucas and Ortlepp (2000) tried to measure the burnout levels of psychiatric 
nurses, the relationship between, and impact of, the various factors in the work environment and those of the nursing staff's role on burnout. They also tried to determine the role of sense of coherence in the relationship between the work environment and burnout levels. Although burnout levels were generally high, psychiatric nurses registered a low sense of personal accomplishment that correlated only with role conflict. Emotional exhaustion and depersonalisation correlated significantly with all the factors of the work environment and with sense of coherence. Multiple regression analyses showed that sense of coherence and workload explain a large proportion of the variance of both emotional exhaustion and depersonalisation, and that role conflict explains a small but significant amount of the variance in personal accomplishment. No research was found in the health industry or nursing field on sense of coherence and the relationship between job satisfaction and organisational culture.

\section{Self-efficacy, job satisfaction and organisational culture}

Bandura and Wood (1989) found a relation among perceived controllability, self-efficacy, and performance. More specifically, their research indicated that participants in a simulated organisation who operated under a cognitive set of low organisational controllability, displayed low self-efficacy even when standards were within easy reach or where organisational goals were lowered. On the other hand, participants who operated under a cognitive set that organisations are controllable, maintained a strong sense of self-efficacy, set challenging goals and exhibited effective analytical thinking. It was found that, as individuals begin to form a self-schema of their efficacy through further experience, the performance system was influenced more strongly and intricately through their conceptions of self-efficacy. It follows that jobs that enhance situational and personal control also have the potential to lead to higher self-management efficacy beliefs. Jimmieson (2000) conducted research using a sample of 100 customer service representatives. The evidence suggests that self-efficacy moderates the main effects of work control on job satisfaction and somatic health.

Busch, Fallan and Pettersen (1998) conducted a study in which they explored the differences in performance indicators among faculty employees of the nursing, teacher education, engineering and business administration programs in the Norwegian college sector. The research focused on performance indicators such as job satisfaction, self-efficacy, goal commitment and organisational commitment in the college sector, and on where these indicators differ in faculties of nursing, teacher education, engineering and business administration. The study revealed statistically significant differences in the subject-specific norms. The scores of the nursing programme faculties were significantly lower than the scores of other programmes. There were no significant differences between the employees of the business administration, teacher education and engineering programs regarding self-efficacy research. There were significant differences in organisational commitment between employees in the four educational programmes. The highest commitment among the faculties in the schools of nursing and the lowest scores were found among the employees in the engineering and business administration programmes.

Very little research on the mediating effect of personality variables on the relationship between job satisfaction and organisational culture was found, indicating a void in this area and thus the relevance of this study.

\section{Research objectives}

The primary research objective of this study is to:

Determine the predictors (biographic, job satisfaction and personality variables) of subjectively perceived organisational culture.
The secondary objectives are to determine:

1. the predictors (biographic and personality variables) of job satisfaction, and

2. whether the relationship between job satisfaction and subjectively perceived organisational culture is mediated by personality variables.

In essence, the model depicted in Figure 1 will be tested in this study. (Please note that the arrows in all the models do not suggest causality, but only the direction of prediction.)

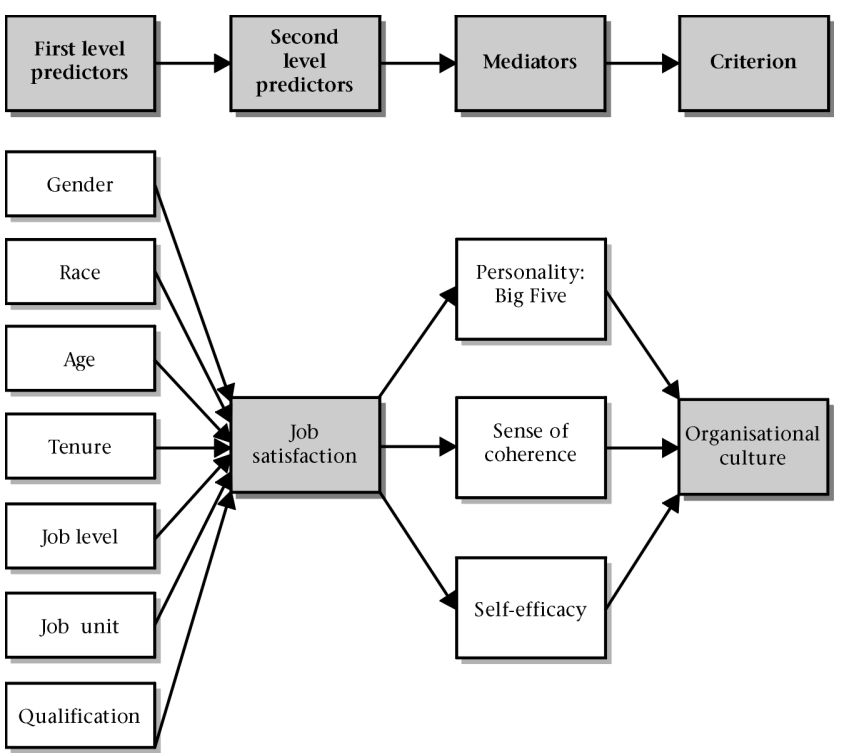

Figure 1: Prediction model of perceived organisational culture

\section{RESEARCH DESIGN}

\section{Research approach}

A cross-sectional, quantitative approach was followed in this study where primary data was generated by using standardised instruments in a non-random field survey. Correlational procedures for data analyses were applied to explain observations on an ex post facto basis.

\section{Participants}

A countrywide sample of convenience drawn from a population of nurses $(\mathrm{N}=3456)$ working for a national health-service provider yielded 713 completed questionnaires obtained in multiple sessions. This represents a response rate of $21 \%$. The sample consisted mainly of women (93\%) and a small group of men $(6 \%)$. The majority of the sample were Afrikaans speaking (61\%) opposed to $24 \%$ English speakers and $15 \%$ others. The sample was mainly white (66\%) followed by coloureds/asians $(18 \%)$ and blacks $(15 \%)$.

\section{Measuring instruments}

The measuring instrument consisted of six sections. Section 1 solicited biographical information from the respondents. Section 2 was the 29-item Sense of Coherence Scale (SOC) of Antonovsky (1993); Section 3 was the 27-item Self-Efficacy (SE) Scale of Sherer, Maddux et al. (1982); Section 4 was the 100item Five Factor Personality Inventory of Hendrikz, Hofstee, et al. (1995) [adapted by Schepers (2003)]; Section 5 was the 100item Organisational Culture Questionnaire of Van der Post, De Coning and Smith (1997); and Section was 6 the 100-item Minnesota Satisfaction Questionnaire of Weiss, Dawes, England and Lofquist (1967). A seven-point intensity response scale anchored at the extreme ends was used for all the questionnaires. 
TABLE 1

SUMMARY OF PARTICIPANTS' BIOGRAPHIC DETAILS $(\mathbf{N}=\mathbf{7 1 3})$

\begin{tabular}{lcc}
\hline Demographic variable & N & $\%$ \\
\hline 1. Gender & 42 & 6 \\
Male & 664 & 93 \\
Female & 706 & 99 \\
Total & & \\
2. Language & 437 & 61 \\
Afrikaans & 168 & 24 \\
English & 108 & 15 \\
Other & 713 & 100 \\
Total & & \\
3. Race & & 66 \\
White & 469 & 18 \\
Coloured/Asians & 128 & 15 \\
Black & 103 & 99 \\
Total & 700 & \\
\hline
\end{tabular}

Note: unequal totals are ascribed to missing values

\section{Procedure}

The questionnaires were compiled in book form and completed manually by the respondents. The questionnaires were completed under normal, standardised classroom conditions. The procedure described above allowed for some measure of control over the test material in the sense that all the questionnaires, whether completed or not, were collected. Participation was voluntary and the anonymity of the respondents was guaranteed. The respondents were fully informed about the purpose of the research.

\section{RESULTS}

The analysis of the data was conducted in two stages. The objective of the first stage was to establish whether all the variables were robust and reliable. In order to achieve this, all the measuring instruments were factor-analysed separately on two levels. This procedure was suggested by Schepers (1992) to avoid the creation of artificial factors.

In the first level analysis, all the items of each measuring instrument were inter-correlated and an anti-image correlation was executed to test the suitability of the matrix for factor analysis by referring to the Kaiser-Meyer-Olkin Measure of Sampling Adequacy and Bartlett's Test of Sphericity. Eigenvalues were calculated on the unreduced item inter-correlation matrix and a number of factors were postulated according to Kaiser's (1970) criterion of eigenvalues larger than unity.

In the second level analysis, sub-scores for each postulated factor were calculated and the same procedure, as explained above, was repeated on the sub-score inter-correlation matrices. Items of the obtained second level factors (scales) were subjected to iterative item analyses to establish the internal consistency of each scale. Based on this procedure, the following reliabilities (Cronbach Alphas) were obtained for each scale:

The Job Satisfaction questionnaire yielded three scales: imposed personal demands $(0,92)$; intrinsic satisfaction $(0,94)$; and extrinsic satisfaction $(0,95)$. The Five Factor Personality Inventory yielded five factors: emotional stability $(0,85)$; openness to experience $(0,75)$; conscientiousness $(0,92)$; extraversion $(0,80)$; and agreeableness $(0,69)$. The SOC Scale $(0,88)$ and the Self-Efficacy Scale $(0,87)$ yielded one scale each. The Organisational Culture questionnaire yielded two scales: goal directedness (GD) $(0,92)$ and internal climate (IC) $(0,97)$.

The three job satisfaction scales (imposed personal demands and extrinsic and intrinsic satisfaction) were significantly $(\mathrm{p}<0,05$; except for values indicated with an $\left.{ }^{*}\right)$ related to SOC $(0,507$; $0,422 ; 0,443)$, SE $(-0,309 ;-0,221 ;-0,300)$, Emotional Stability (0,$\left.188 ;-0,102^{*} ;-0,228\right)$, Openness to Experience $\left(-0,145 ;-0,019^{*}\right.$; $\left.-0,068^{*}\right)$, Conscientiousness $(0,372 ; 0,215 ; 0,327)$, Extraversion $\left(0,119 ; 0,021^{*} ; 0,046^{*}\right)$, and Agreeableness $\left(0,122 ; 0,095^{*} ; 0,141\right)$

Scores on all three job satisfaction scales (Imposed Personal Demands, and Extrinsic and Intrinsic Satisfaction) were significantly ( $p<0,05)$, positively correlated with the scores on the GD scale $(0,537 ; 0,480$ and 0,381 respectively), whereas the same scores were significantly $(\mathrm{p}<0,000)$ negatively correlated with the scores on the IC scale $(-0,218 ;-0,492$ and $-0,310)$.

In applying the General Linear Model (GLM) for all the models that follow below, an iterative procedure was used to determine the least number of variables that explain the highest amount of variance in the criterion. Residuals were systematically analysed to investigate the interaction effect with the criterion variable. The regression equations finally proposed are all based on the obtained unstandardised B-values and the equations will also be displayed in the text.

When looking at the organisational culture dimensions, Goal Directedness and Internal Climate, significant predictors were found. When applying a GLM with biographical variables, job satisfaction and personality variables (SOC, SE and Five Personality factors) as predictors of Goal Directedness (GD), $40 \%\left(r^{2}=0,399\right)$ of the variance were predicted by Personal Demands, Agreeableness depending on the Hospital Type, Selfefficacy, Extrinsic Satisfaction and Extraversion, depending on the hospital type. See Table 2 for the summary model and Table 3 for the obtained B-values.

TABLE 2

MODEL SUMMARY FOR GLM: GOAL DIRECTEDNESS

\begin{tabular}{lllll}
\hline Model & R & $\begin{array}{c}\text { Model Summary } \\
\text { R Square }\end{array}$ & $\begin{array}{l}\text { Adjusted R R } \\
\text { Square }\end{array}$ & $\begin{array}{l}\text { Std. Error of } \\
\text { the Estimate }\end{array}$ \\
\hline 1 & $0,528(\mathrm{a})$ & 0,279 & 0,277 & 0,68468 \\
2 & $0,600(\mathrm{~b})$ & 0,360 & 0,357 & 0,64586 \\
3 & $0,620(\mathrm{c})$ & 0,384 & 0,380 & 0,63388 \\
4 & $0,631(\mathrm{~d})$ & 0,398 & 0,393 & 0,62765 \\
5 & $0,637(\mathrm{e})$ & 0,405 & 0,399 & 0,62447
\end{tabular}

a Predictors: (Constant), Personal demands

b Predictors: (Constant), Personal demands, Agreeableness $\times$ Hospital Type $(\mathrm{HT}$

c Predictors: (Constant), Personal demands, Agreeableness $\times$ HT, Self-efficacy

d Predictors: (Constant), Personal demands, Agreeableness $\times$ HT, Self-efficacy, Extrinsic

Motivation

e Predictors: (Constant), Personal demands, Agreeableness $\times$ HT, Self-efficacy, Extrinsic Motivation, Extraversion $\times \mathrm{HT}$

TABLE 3

STATISTCAL PARAMETERS OF PREDICTOR VARIABLES FOR GOAL DIRECTEDNESS

\begin{tabular}{lrccrc}
\hline & $\begin{array}{c}\text { Unstandardised } \\
\text { Coefficients }\end{array}$ & $\begin{array}{c}\text { Standardised } \\
\text { Coefficients }\end{array}$ & $\mathbf{t}$ & Sig. \\
\hline Model & B & Std. Error & Beta & & \\
(Constant) & 3,233 & 0,264 & & 12,224 & 0,000 \\
Personal Demands & $-0,344$ & 0,049 & 0,332 & 6,996 & 0,000 \\
Agreeableness $\times$ & 0,157 & 0,034 & 0,509 & 4,664 & 0,000 \\
Hospital Type & & & & & \\
Self-efficacy & $-0,169$ & 0,042 & $-0,151$ & $-3,997$ & 0,000 \\
Extrinsic Satisfaction & 0,105 & 0,036 & 0,136 & 2,951 & 0,003 \\
Extraversion $\times$ & $-0,0970$ & 0,41 & 0,260 & $-2,389$ & 0,017 \\
Hospital Type & & & & & \\
\hline
\end{tabular}

a Dependent Variable: Goal Directedness 
Based on the obtained statistical parameters of the different predictor variables, the following equation was formulated to predict GD.

GD $=3,233+0,344$ Imposed Personal Demands $+0,157$ Agreeableness $\times$ Hospital type $-0,169$ Self-efficacy $+0,105$ Extrinsic Satisfaction $-0,0971$ Extraversion $\times$ Hospital type

See Figure 2 for a graphical representation of the predictors of GD.

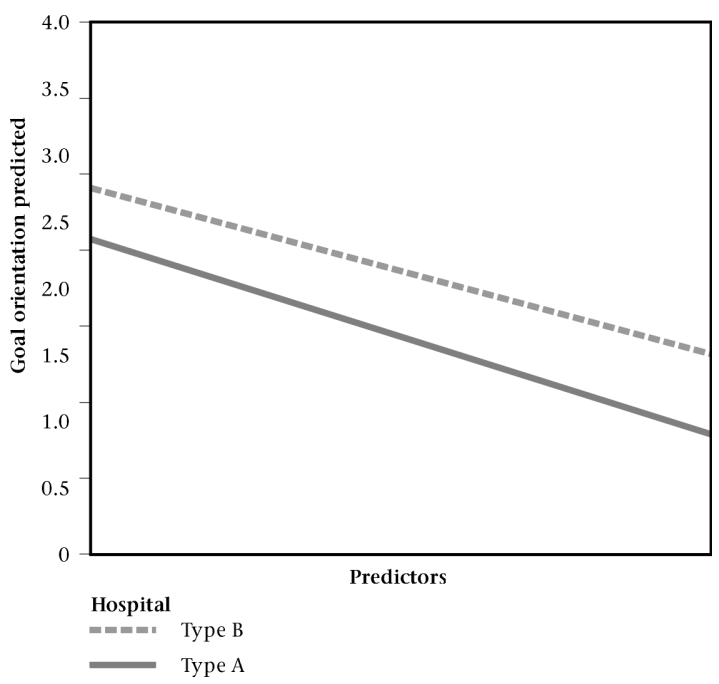

Figure 2: Predictors of Goal Directedness (GD)

In applying the GLM with biographical variables, personality variables and job satisfaction as predictors of Internal Climate (IC), $21 \%\left(r^{2}=0,205\right)$ of the variance was predicted by Extrinsic Satisfaction depending on hospital type, Conscientiousness depending on diploma and specialised diploma (DSD), Conscientiousness depending on unit of work, namely Cardiac Thoracic Intensive Care Unit (CTICU), and Self-efficacy depending on DSD. See Table 4 for the summary model and Table 5 for the obtained B-values.

TABLE 4

MODEL SUMMARY FOR GLM: INTERNAL CLIMATE

\begin{tabular}{lllll}
\hline Model & R & $\begin{array}{c}\text { Model Summary } \\
\text { R Square }\end{array}$ & $\begin{array}{l}\text { Adjusted R R } \\
\text { Square }\end{array}$ & $\begin{array}{l}\text { Std. Error of } \\
\text { the Estimate }\end{array}$ \\
\hline 1 & $0,270(\mathrm{a})$ & 0,073 & 0,070 & 0,94804 \\
2 & $0,439(\mathrm{~b})$ & 0,192 & 0,188 & 0,88585 \\
3 & $0,451(\mathrm{c})$ & 0,203 & 0,197 & 0,88109 \\
4 & $0,462(\mathrm{~d})$ & 0,213 & 0,205 & 0,87671 \\
\hline
\end{tabular}

a Predictors: (Constant), ES $\times$ Diploma or Specialised Diploma (DSD)

b Predictors: (Constant), ES $\times$ DSD, Conscientiousness $x$ DSD

c Predictors: (Constant), ES $\times$ DSD, Conscientiousness $x$ DSD, Conscientiousness $\times$ Cardiac Thoracic Intensive Care Unit (CTICU)

d Predictors: (Constant), ES x DSD, Conscientiousness x DSD, Conscientiousness $\times$

CTICU, SE $\times$ DSD

Based on the obtained statistical parameters of the different predictor variables, the following equation was formulated to predict IC.

IC $=4,770-0,151$ Extrinsic Satisfaction $\times$ DSD $+0,09228$

Conscientiousness $\times$ DSD $+0,102$ Conscientiousness $\times$ CTICU $+0,04160$ Self-efficacy $\times$ DSD.

Refer to Figure 3 for a model depicting the prediction of IC.
TABLE 5

STATISTICAL PARAMETERS OF PREDICTOR VARIABLES FOR INTERNAL CLIMATE

\begin{tabular}{|c|c|c|c|c|c|}
\hline \multirow[b]{2}{*}{ Model } & \multicolumn{2}{|c|}{$\begin{array}{l}\text { Unstandardised } \\
\text { Coefficients }\end{array}$} & \multirow{2}{*}{$\begin{array}{c}\begin{array}{c}\text { Standardised } \\
\text { Coefficients }\end{array} \\
\text { Beta }\end{array}$} & \multirow[t]{2}{*}{$t$} & \multirow[t]{2}{*}{ Sig. } \\
\hline & B & Std. Error & & & \\
\hline (Constant) & 4,770 & 0,121 & & 39,470 & 0,000 \\
\hline $\begin{array}{l}\text { Extrinsic } \\
\text { Satisfaction } \times \\
\text { Diploma or } \\
\text { Specialised Diploma } \\
\text { (DSD) }\end{array}$ & $-0,151$ & 0,015 & $-0,768$ & $-9,830$ & 0,000 \\
\hline $\begin{array}{l}\text { Conscientiousness } \\
\times \text { DSD }\end{array}$ & 0,09228 & 0,015 & 0,505 & 5,960 & 0,000 \\
\hline $\begin{array}{l}\text { Conscientiousness } \\
\times \text { Cardiac Thoracic } \\
\text { Intensive Care Unit } \\
(\text { CTICU) }\end{array}$ & 0,102 & 0,045 & 0,102 & 2,267 & 0,024 \\
\hline $\begin{array}{l}\text { Self Efficacy } \\
\times \text { DSD }\end{array}$ & 0,04160 & 0,019 & 0,136 & 2,223 & 0,027 \\
\hline
\end{tabular}

a Dependent Variable: Internal Climate

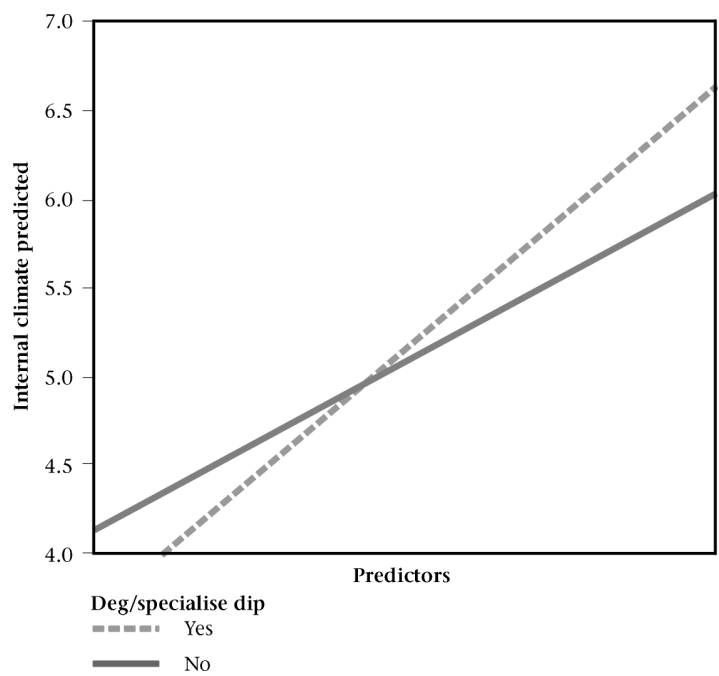

Figure 3: Predictors of Internal Climate

In applying the General Linear Model (GLM) with biographical variables and personality variables as predictors of Imposed Personal Demands (IPD), $23 \%\left(\mathrm{r}^{2}=0,226\right)$ of the variance of IPD was explained. See Table 6 for the summary model and Table 7 for the obtained B-values of the different predictors.

TABLE 6

MODEL SUMMARY FOR GLM: IMPOSED PERSONAL DEMANDS

\begin{tabular}{lllll}
\hline Model & $\mathbf{R}$ & $\begin{array}{c}\text { Model Summary } \\
\text { Adjusted R } \\
\text { Square }\end{array}$ & $\begin{array}{l}\text { Std. Error of } \\
\text { the Estimate }\end{array}$ \\
\hline 1 & $0,320(\mathrm{a})$ & 0,103 & 0,101 & 0,76344 \\
2 & $0,411(\mathrm{~b})$ & 0,169 & 0,166 & 0,73546 \\
3 & $0,468(\mathrm{c})$ & 0,219 & 0,214 & 0,71366 \\
4 & $0,477(\mathrm{~d})$ & 0,227 & 0,221 & 0,71043 \\
5 & $0,483(\mathrm{e})$ & 0,233 & 0,226 & 0,70845 \\
\hline
\end{tabular}

a Predictors: (Constant), Conscientiousnes

b Predictors: (Constant), Conscientiousness, Extraversion $\times$ Hospital Type $(\mathrm{HT})$

c Predictors: (Constant), Conscientiousness, Extraversion $\times$ HT, Openness to Experience

c Predictors: (Constant), Conscientiousness, Extraversion $\times$ HT, Openness to Experience
d Predictors: (Constant), Conscientiousness, Extraversion $\times$ HT, Openness to Experience, d Predictors: (Constant)

e Predictors: (Constant), Conscientiousness, Extraversion $\times$ HT, Openness to Experience, Emotional Stability, Agreeableness 
TABLE 7

STATISTICAL PARAMETERS OF PREDICTOR VARIABLES FOR IMPOSED PERSONAL DEMANDS

\begin{tabular}{|c|c|c|c|c|c|}
\hline \multirow[b]{2}{*}{ Model } & \multicolumn{2}{|c|}{$\begin{array}{l}\text { Unstandardised } \\
\text { Coefficients }\end{array}$} & \multirow{2}{*}{$\begin{array}{c}\begin{array}{c}\text { Standardised } \\
\text { Coefficients }\end{array} \\
\text { Beta }\end{array}$} & \multirow[t]{2}{*}{$\mathrm{t}$} & \multirow[t]{2}{*}{ Sig. } \\
\hline & B & Std. Error & & & \\
\hline (Constant) & 4,738 & 0,413 & & 11,481 & 0,000 \\
\hline Conscientiousness & 0,377 & 0,049 & 0,314 & 7,759 & 0,000 \\
\hline $\begin{array}{l}\text { Extraversion } \times \\
\text { Hospital Type }\end{array}$ & 0,08670 & 0,014 & 0,233 & 6,013 & 0,000 \\
\hline $\begin{array}{l}\text { Openness to } \\
\text { Experience }\end{array}$ & $-0,263$ & 0,044 & $-0,245$ & $-5,971$ & 0,000 \\
\hline Emotional Stability & $-0,132$ & 0,046 & $-0,115$ & $-2,872$ & 0,004 \\
\hline Agreeableness & $-0,08299$ & 0,041 & $-0,084$ & $-2,005$ & 0,045 \\
\hline
\end{tabular}

a Dependent Variable: Personal Demands

Based on the obtained statistical parameters of the different predictor variables, the following equation was formulated to predict IPD.

IPD $=4,738+0,377$ Conscientiousness $+0,0867$ Extraversion $\times$ Hospital type $-0,263$ Openness to experience $-0,132$ Emotional stability - 0,083 Agreeableness

In Figure 4 a predictive model for IPD is provided.

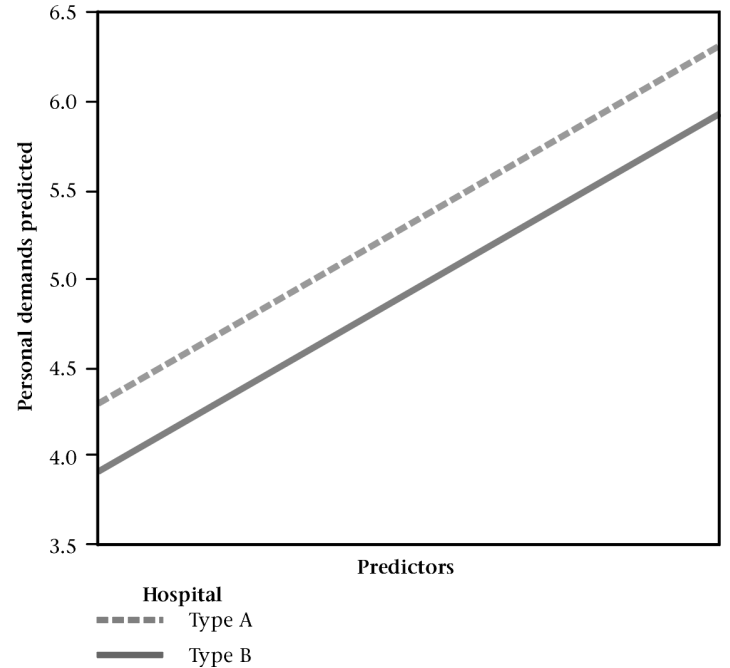

Figure 4: Predictors of Imposed Personal Demands

In applying the General Linear Model (GLM) with only biographical variables and personality variables as predictors of Extrinsic Satisfaction (ES), the following variables emerged as significant predictors, which explain $11 \%\left(\mathrm{r}^{2}=0,114\right)$ of the variance of ES. Refer to Table 8 for the summary model and Table 9 for the corresponding B-values of the predictors.

Based on the obtained statistical parameters of the different predictor variables, the following equation was formulated to predict ES.

\footnotetext{
$\mathrm{ES}=+4,045+0,160$ Agreeableness $\times$ Hospital type $-0,311$

Emotional stability $\times$ Hospital type $+0,145$

Conscientiousness x Hospital type.
}

Figure 5 is a graphical presentation of the model predicting ES.
In applying the General Linear Model (GLM) with biographical variables and personality variables as predictors of Intrinsic Satisfaction (IS), the following variables that emerged as significant predictors explained $13 \%\left(\mathrm{r}^{2}=0,127\right)$ of the variance in IS. Refer to Table 10 for the summary model and Table 11 for the $\mathrm{B}$-values of the different predictor variables.

TABLE 8

MODEL SUMMARY FOR GLM: EXTRINSIC SATISTFACTION

\begin{tabular}{lllll}
\hline Model & $\mathbf{R}$ & $\begin{array}{c}\text { Model Summary } \\
\text { R Square }\end{array}$ & $\begin{array}{l}\text { Adjusted R } \\
\text { Square }\end{array}$ & $\begin{array}{l}\text { Std. Error of } \\
\text { the Estimate }\end{array}$ \\
\hline 1 & $0,278(\mathrm{a})$ & 0,078 & 0,076 & 0,97753 \\
2 & $0,331(\mathrm{~b})$ & 0,110 & 0,106 & 0,96124 \\
3 & $0,345(\mathrm{c})$ & 0,119 & 0,114 & 0,95711 \\
\hline
\end{tabular}

a Predictors: (Constant), Agreeableness $\times$ HT

b Predictors: (Constant), Agreeableness $\times$ HT, Emotional Stability $\times$ HT

c Predictors: (Constant), Agreeableness $\times$ HT, Emotional Stability $\times$ HT, Conscientiousness

TABLE 9

STATISTICAL PARAMETERS OF PREDICTOR VARIABLES FOR EXTRINSIC SATISFACTION

\begin{tabular}{|c|c|c|c|c|c|}
\hline \multirow[b]{2}{*}{ Model } & \multicolumn{2}{|c|}{$\begin{array}{l}\text { Unstandardised } \\
\text { Coefficients }\end{array}$} & \multirow{2}{*}{$\begin{array}{c}\begin{array}{c}\text { Standardised } \\
\text { Coefficients }\end{array} \\
\text { Beta }\end{array}$} & \multirow[t]{2}{*}{$t$} & \multirow[t]{2}{*}{ Sig. } \\
\hline & B & Std. Error & & & \\
\hline (Constant) & 4,045 & 0,060 & & 67,843 & 0,000 \\
\hline $\begin{array}{l}\text { Agreeableness } \times \\
\text { Hospital Type }\end{array}$ & 0,160 & 0,058 & 0,411 & 2,785 & 0,006 \\
\hline $\begin{array}{l}\text { Emotional Stability } \\
\times \text { Hospital Type }\end{array}$ & $-0,311$ & 0,062 & $-0,568$ & $-5,030$ & 0,000 \\
\hline $\begin{array}{l}\text { Conscientiousness } \\
\times \text { Hospital Type }\end{array}$ & 0,145 & 0,061 & 0,401 & 2,381 & 0,018 \\
\hline
\end{tabular}

A Dependent Variable: Extrinsic Satisfaction

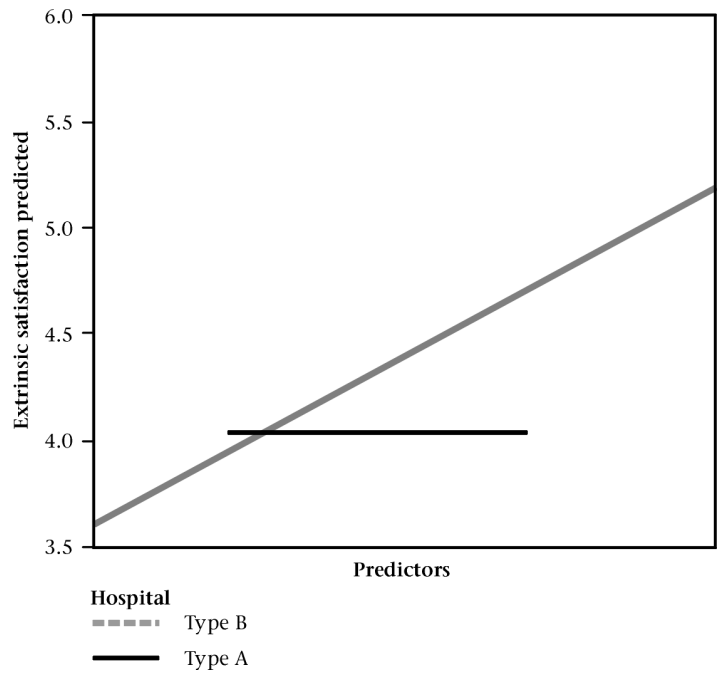

Figure 5: Predictors of Extrinsic Satisfaction

Based on the obtained statistical parameters of the different predictor variables, the following equation was formulated to predict IS.

IS $=+3,460+0,323$ Conscientiousness $+0,0563$ Agreeableness $\times$ Hospital type $-0,172$ Emotional stability 
TABLE 10

MODEL SUMMARY FOR GLM: INTRINSIC SATISTFACTION

\begin{tabular}{lllll}
\hline Model & R & $\begin{array}{c}\text { Model Summary } \\
\text { R Square }\end{array}$ & $\begin{array}{l}\text { Adjusted R } \\
\text { Square }\end{array}$ & $\begin{array}{l}\text { Std. Error of } \\
\text { the Estimate }\end{array}$ \\
\hline 1 & $0,296(\mathrm{a})$ & 0,088 & 0,086 & 0,87012 \\
2 & 0,339 (b) & 0,115 & 0,112 & 0,85793 \\
3 & 0,363 (c) & 0,132 & 0,127 & 0,85051 \\
\hline
\end{tabular}

a Predictors: (Constant), Conscientiousness

b Predictors: (Constant), Conscientiousness, Agreeableness $\times$ HT

c Predictors: (Constant), Conscientiousness, Agreeableness $\times$ HT, Emotional Stability

TABLE 11

STATISTICAL PARAMETERS OF PREDICTOR VARIABLES FOR INTRINSIC SATISFACTION

\begin{tabular}{lccccc}
\hline & \multicolumn{1}{c}{$\begin{array}{c}\text { Unstandardised } \\
\text { Coefficients }\end{array}$} & $\begin{array}{c}\text { Standardised } \\
\text { Coefficients }\end{array}$ & t & Sig. \\
\hline Model & B & Std. Error & Beta & & \\
\hline (Constant) & 3,460 & 0,390 & & 8,870 & 0,000 \\
Conscientiousness & 0,323 & 0,057 & 0,237 & 5,673 & 0,000 \\
Agreeableness $\times$ & 0,05634 & 0,014 & 0,161 & 3,912 & 0,000 \\
Hospital Type & & & & & \\
Emotional Stability & $-0,172$ & 0,053 & $-0,133$ & $-3,227$ & 0,001 \\
\hline
\end{tabular}

a Dependent Variable: Intrinsic Satisfaction

The graphical display of the prediction of IS appears in Figure 6.

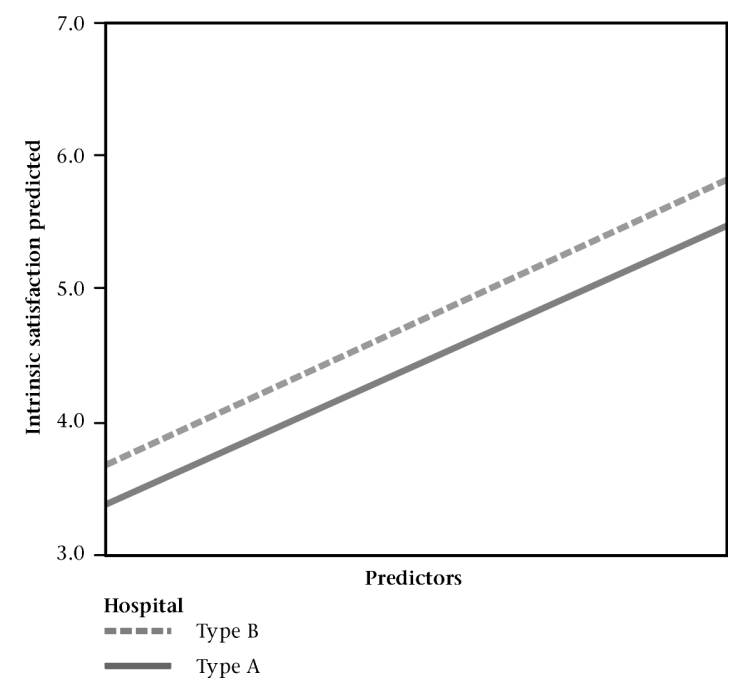

Figure 6: Predictors of Intrinsic Satisfaction

\section{DISCUSSION}

The first and second level factor analyses of the different measuring instruments, followed by iterative item analyses, yielded scales with acceptable coefficient Alphas, (ranging from 0,69 to 0,95 ) indicating that all the respective scales were suitable for inclusion in the second phase of the data analysis.

The inter-correlations of the variables show that the three scales of job satisfaction (Imposed Personal Demands, Intrinsic Satisfaction and Extrinsic Satisfaction) are positively related $(+0,537 ;+0,381$ and $+0,480$ respectively) to perceived Goal Directedness, but negatively related $(-0,218 ;-0,310$ and $-0,492$ respectively) to the perceived Internal Climate of organisational culture. This finding suggests that the perceived Internal
Climate of the organisation is negatively correlated with satisfaction dimensions as opposed to perceived Goal Directedness. This finding only partially supports other research of reported significant correlations between organisational culture and job satisfaction (Coetzee, 1999; Tzeng, et al, 2002), and significant positive correlations (Sempane et al., 2002) between overall job satisfaction and organisational culture $(r=0,743)$. The current study also used job satisfaction as a predictor of organisational culture and not vice versa. No other studies were found to support the results in terms of the two dimensions found in this study.

The findings of the two GLMs that predict Goal Directedness and Internal Climate suggest that the following theoretical models could be compiled from the empirical evidence for predicting organisational culture.

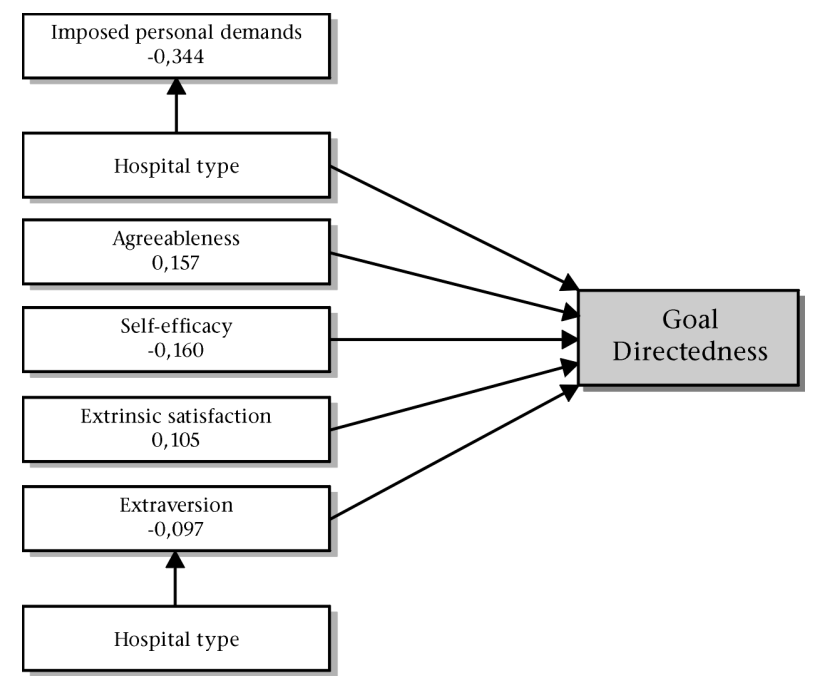

Figure 7: Biographical variables, job satisfaction and personality variables as predictors of GD

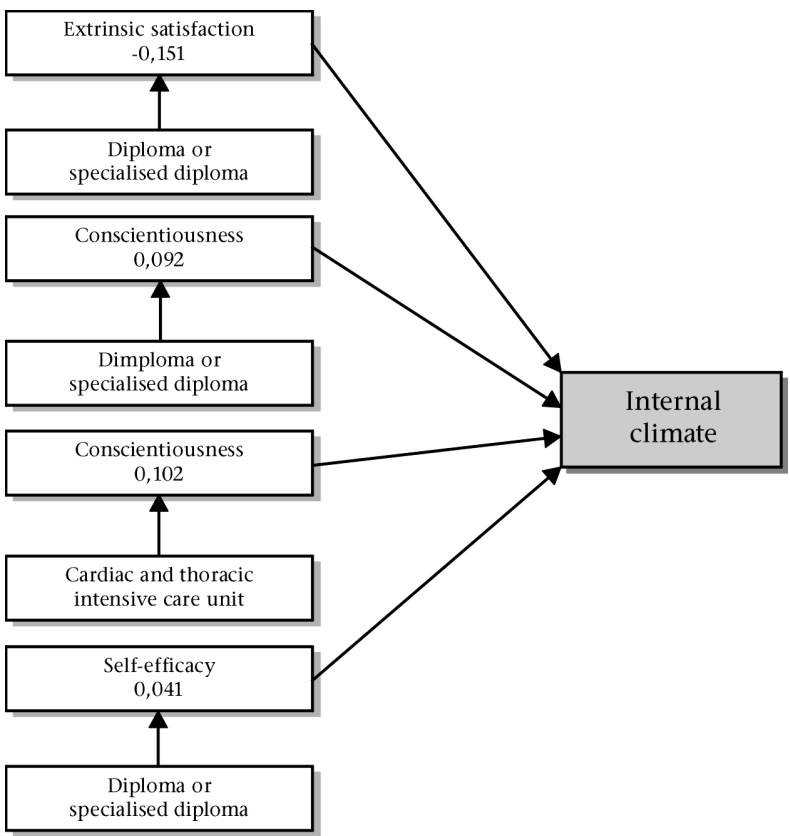

Figure 8: Biographical variables, job satisfaction and personality variables as predictors of IC

The following variables emerged as significant predictors of Goal Directedness where $40 \%$ of the variance was explained, namely Imposed Personal Demands (negative B-value), Agreeableness, Self-efficacy (negative B-value), Extrinsic 
Satisfaction and Extraversion (negative B-value). Both Agreeableness and Extraversion interacted with Hospital type. The findings suggest that the respondents who exhibit lower scores on Imposed Personal Demands, Self-efficacy and Extraversion (dependent on Hospital type) perceived a greater degree of Goal Directedness. Higher scores on Agreeableness (dependent on Hospital type) and Extrinsic Satisfaction also result in higher levels of perceived Goal Directedness. These findings correspond somewhat with other research findings (Gerhardt, 1987; Staw \& Ross, 1985) in that previous job satisfaction seems to be a significant predictor of current job satisfaction, rather than salary and job complexity. Furthermore, that personality dispositions (as opposed to learned behaviour), influence job satisfaction more decisively than organisational factors. In this study, the type of hospital influenced the perception of the participants with regard to Goal Directedness as predicted by personality variables.

Based on the model for the prediction of Internal Climate where $21 \%$ of the variance was explained, the following variables emerged as significant predictors, namely Extrinsic Satisfaction, Conscientiousness and Self-efficacy. A degree and specialised diploma significantly interacts with Extrinsic Satisfaction (negative B-value), Conscientiousness and Self-efficacy, while working in the Cardiac intensive care unit interacts with Conscientiousness. The respondents who are conscientious and self-efficacious will perceive the Internal Climate more positively, while the respondents with lower Extrinsic Satisfaction scores will perceive Internal Climate more positively. Although the current study's results do not support other research findings, some similarity could be found with the research by Miller et al. (1999). They found that conscientiousness reduced the impact of role clarity on both psychological distress and job satisfaction. Griffen, Dunbar and McGill (1978) reported a relationship between educational level and job satisfaction indicating that workers with higher educational levels would tend to be more satisfied with their job than workers with lower educational levels. Previous studies thus refer to a link between conscientiousness, educational level and job satisfaction.

In both cases of Goal Directedness and Internal Climate, job satisfaction variables explain more variance in organisational culture than personality variables. Some of the predictor variables were dependent on qualification, work unit or hospital type. Job satisfaction and personality variables are thus predictors of subjectively perceived organisational culture. These findings also suggest that personality variables do not mediate the relationship between job satisfaction and organisational culture variables. Hereby, the primary objective and a secondary objective of the study were achieved.

The findings of the three GLMs predicting Imposed Personal Demands, Extrinsic Satisfaction and Intrinsic Satisfaction provide empirical evidence for predicting job satisfaction and hence suggest the following three theoretical models.

In the prediction of Imposed Personal Demands, where $23 \%$ of the variance was explained, the following variables emerged as significant predictors, namely Conscientiousness, Extraversion, Openness to Experience (negative B-value), Emotional Stability (negative B-value) and Agreeableness (negative B-value). Conscientiousness and Extraversion are positively related to Imposed Personal Demands. This model suggests that Imposed Personal Demands are mainly predicted by personality variables. The study of Seibert and Kraimer (2001) support this finding with regard to neuroticism (beta $=$ $-0,20 ; \mathrm{p}<0,01$ ), agreeableness (beta $=-0,09 ; \mathrm{p}<0,01$ ) and openness to experience (beta $=-0,10 ; p<0,01$ ) when predicting career satisfaction. The zero-order correlation also indicated that neuroticism was related negatively to career satisfaction ( $\mathrm{r}$ $=-0,21 ; p<0,01)$. Extraversion was also related significantly to career satisfaction (beta $=0,15 ; \mathrm{p}<0,01$ ).

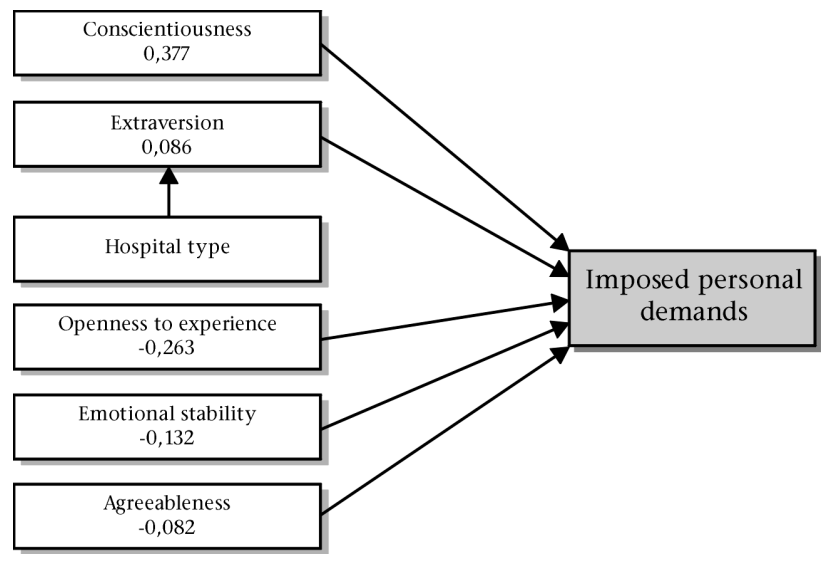

Figure 9: Biographical variables and personality variables as predictors of Imposed Personal Demands

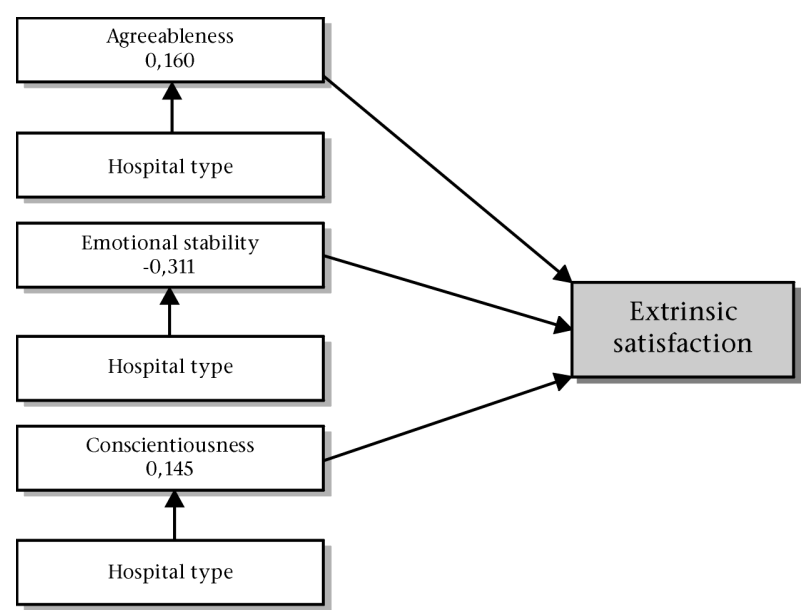

Figure 10: Biographical variables and personality variables as predictors of Extrinsic Satisfaction

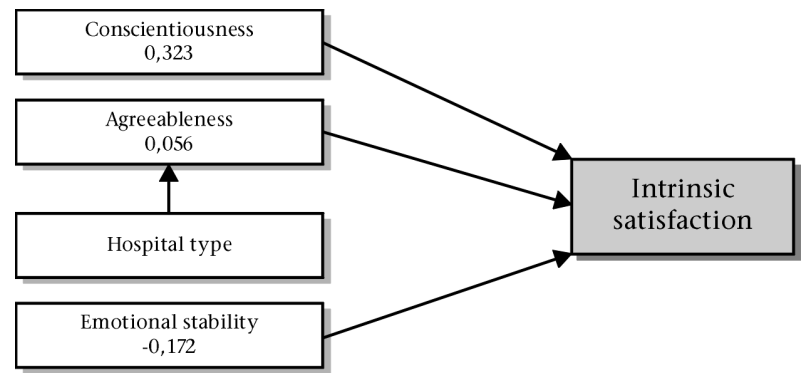

Figure 11: Biographical variables and personality variables as predictors of Intrinsic Satisfaction

The following variables emerged as significant predictors of Extrinsic Satisfaction where $11 \%$ of the variance was explained, namely Agreeableness, Emotional Stability (negative B-value) and Conscientiousness. All three variables are dependent on the Hospital Type. Lower Emotional Stability scores will result in higher Extrinsic Satisfaction. This model suggests that Extrinsic Satisfaction is mainly predicted by personality variables. Judge, Higgins, Thoresen and Barrick (1999), Turban and Dougherty (1994) as well as Tellegen (1985) support the finding with regard to Emotional Stability in that a negative relationship between neuroticism and the composite measure of extrinsic career success was found. Judge et al. (1999) also found a positive relationship between conscientiousness and extrinsic career success. 
The following variables emerged as significant predictors of Intrinsic Satisfaction where $13 \%$ of the variance was explained, namely Conscientiousness, Agreeableness (dependent on Hospital type) and Emotional Stability (negative B-value). Lower Emotional Stability scores will result in higher levels of Intrinsic Satisfaction. This model suggests that Intrinsic Satisfaction is mainly predicted by personality variables. This study supports Judge (1992) who found a negative relationship between neuroticism and intrinsic satisfaction, while Turban and Dougherty (1994) demonstrated that people characterised by positive affectivity exhibited stability in their levels of job satisfaction over a long period and across many jobs and life changes.

While no research was found that exactly replicated the specific dimensions found in this study, research results support some of the findings in this research. The current study's findings support the studies of Tokar and Subich (1997) and Brief et al. (1995) in that extraverts and neurotics are respectively more and less likely to report job satisfaction. Rothmann and Coetzer (2002) found similar results with pharmaceutical respondents in that job satisfaction had a negative relationship with emotional stability (Neuroticism), and a positive relationship with Extraversion and Conscientiousness. The only difference was with Agreeableness where they found a positive relationship. Organ and Lingl (1995) partly supported this finding with regard to agreeableness and conscientiousness as predictors of work satisfaction. The study of Miller et al. (1999) does not support the results of this study in full and found that neither extraversion nor neuroticism (Emotional Stability) and conscientiousness were significant predictors of job satisfaction. The findings of this study suggest that job satisfaction is predominantly predicted by personality variables, thereby achieving the first secondary objective of the study.

A combined empirical model for predicting subjective organisational culture was compiled from all the previous models (Figures 7 -11) and is depicted in Figure 12.

This model suggests that mainly personality variables are predictors of job satisfaction and not biographical variables, as was originally expected. The variance in subjectively perceived organisational culture is mainly explained by job satisfaction

First level predictors

Second level predictors

Criterion

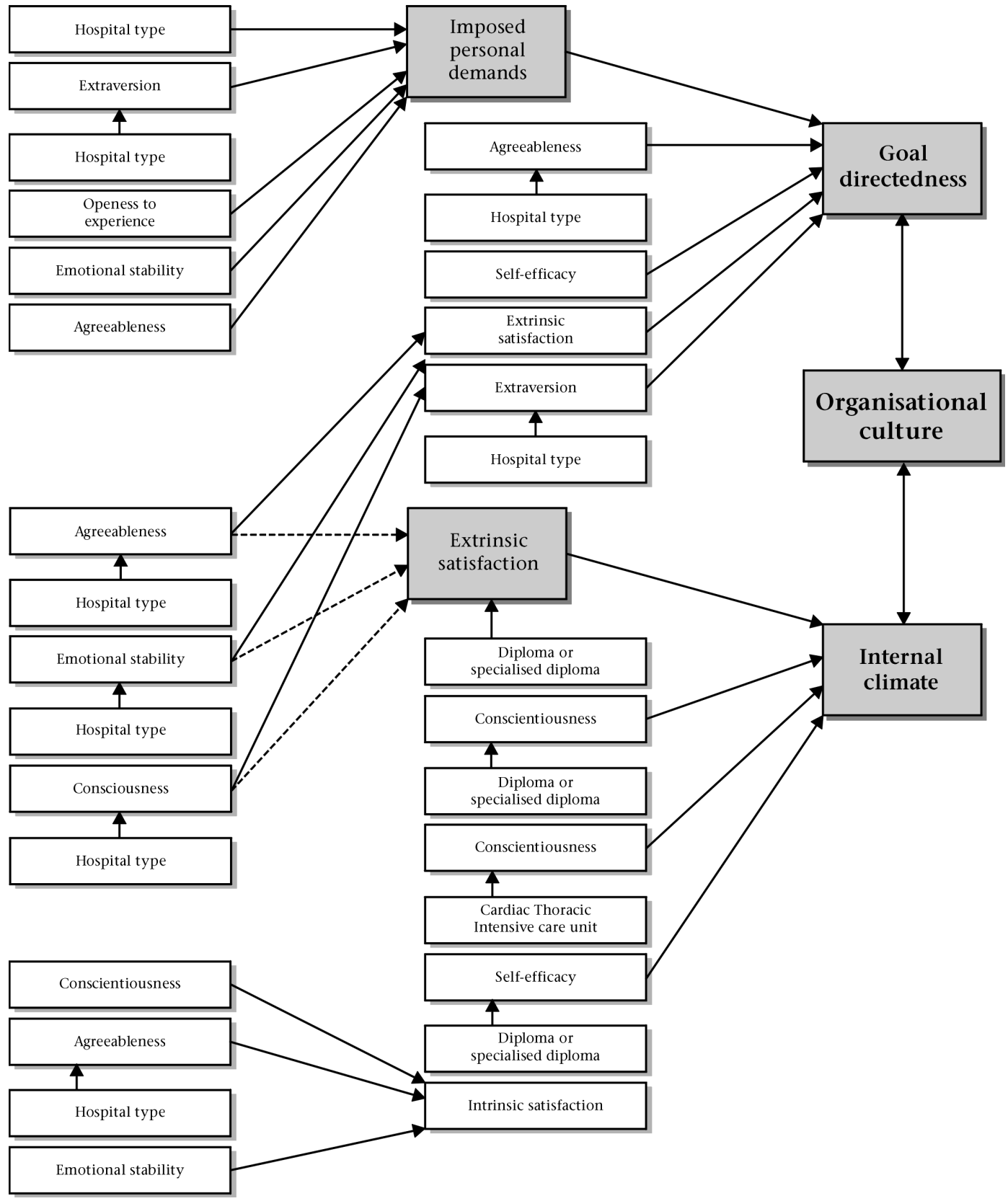

Figure 12: Composite empirical model for predicting subjective organisational cult 
dimensions. The relationship between job satisfaction and organisational culture is in some cases dependent on hospital type, qualification and the type of Intensive Care Unit.

The final empirical model thus suggests that a significant amount of variance of subjectively perceived organisational culture could be explained by these newly established theoretical models. The theoretical model that was initially proposed changed quite dramatically in sequence and in content, which has implications from a theory development perspective. The study also confirmed that subjectively perceived organisational culture is to a large extent explained by dispositional factors such as job satisfaction and personality variables. Stated differently, this means that organisational culture is to a large extent the function of the dispositional factors of the people working in the organisation.

The theoretical implications of the study are highlighted first. From a theory development perspective, the study indicates that dispositional factors (job satisfaction and personality) explain a substantive amount of variance of subjectively perceived organisational culture. Firstly, personality variables mainly predict job satisfaction dimensions and secondly, job satisfaction variables mainly predict perceived organisational culture dimensions. These predictor variables should therefore receive more attention in future research where organisational culture is predicted.

This study also has some important practical implications for the management of organisational culture in this particular organisation. Firstly, it seems that a less desirable personality profile fits the current organisational culture in a particular group of hospitals. Secondly, two distinct types of organisations exist with seemingly different management styles. Thirdly, job satisfaction and organisational culture are manageable variables that can address the turnover problem among professional nurses.

Further suggestions for research are that other personalityrelated variables, such as locus of control, should be included in the prediction of job satisfaction, while the identification of the actual factors of satisfaction or dissatisfaction could add some insight to understanding the subjective experience of organisational culture.

\section{REFERENCES}

Antonovsky, A. (1993). The Structure and properties of the Sense of Coherence Scale. Social Science and Medicine, 36, 725-733.

Argyris, C. (1972). The individual and organization: Some problems of mutual adjustment. In J.H. Turner, A.C. Filley \& R.J. House (eds.) Studies in Managerial Process and Organizational Behavior. Glenview, ILL: Scott, Foresman \& Company.

Argyris, C. (1957). Personality and organisation: The conflict between system and the individual. New York: Harper \& Row, Publishers.

Bandura, A. \& Wood, R. (1989). Effect of perceived controllability and performance standards on selfregulations of complex decision making. Journal of Personality and Social Psychology, 56, 805-814.

Booyens, S.W. (1993). Dimensions of Nursing Management. Juta \& Co Ltd: South Africa.

Brief, A., Butcher, A. \& Roberson, L. (1995). Cookies, disposition, and job attitudes: the effects of positive mood - including events and negative affectivity on job satisfaction in a field experiment. Organisational Behavior and Human Decision Processes, 62, 55-62.

Busch, T., Fallan, L. \& Pettersen, A. (1998). Disciplinary Differences in Job Satisfaction, Self-efficacy, Goal Commitment, and Organisational Commitment among Faculty employees in Norwegian Colleges: An Empirical Assessment of Indicators of Performance. Quality in Higher Education, 2 (4), 137-157.
Calhoun, M. (2002). Healthcare industry review. Maintaining quality of nursing care. Health Annals, 11, 41-43.

Coetzee, D.J. (1999). The connection between organisational culture and work satisfaction among the staff of a manufacturing organisation. Unpublished Masters dissertation, University of the Free State, Bloemfontein.

Cooper, R.W., Frank, G.L., Gouty, C.A. \& Hansen, M.C. (2002). Key Ethical Issues Encountered in Healthcare Organisations - perceptions of Nurse Executives. JONA, 32, 331-337.

Disch, J. (2000). Healthy work environments for all nurses. Journal of Professional Nurses, 16, 75.

Dunnette, M.D. (ed.) (1983). Handbook of Industrial and Organizational Psychology. New York: John Wiley \& Sons.

Furnham, A., Petrides, K.V., Jackson, C.J. \& Cotter, T. (2001). Do personality factors predict job satisfaction? Personality and Individual Differences, 33, 1325-1342.

Gerhardt, B. (1987). How important are dispositional factors as determinants of job satisfaction? Journal of Applied Psychology, 72, 366-373.

Griffen, G.R., Dunbar, R. \& McGill, M. (1978). Factors associated with job satisfaction among police personnel. Journal of Police Science and Administration, 6, 77-85.

Head, T.C. (ed.) (1986). Organizational Behavior: Cases, Exercises, and Readings. Boston, MA: Houghton Mifflin Company

Hendrikz, A.A.J., Hofstee, W.K.B., De Raad, B. \& Angleitner, A. (1995). The Five Factor Personality Inventory [adapted by Schepers, J.M., (2003)]. Johannesburg: RAU press.

Ilies, R. \& Judge, T.A. (2002). Understanding the dynamic relationship among personality, mood, and job satisfaction: A field experience sampling study. Organisational Behavior \& Human Decision Processes, 89, 1119-1140.

Irvine, D.M. \& Evans, M.G. (1995). Job satisfaction and turnover among nurses; integrating research finding across studies. Nursing Research, 44, 246-252.

Jimmieson, N.L. (2000). Employee reactions to behavioural control under conditions of stress: the moderating role of self efficacy. Work \& Stress, 14, 262-280.

Judge, T.A. (1992). The dispositional perspective in human resources research. In G.R. Ferris \& Rollings (Eds). Research in personnel and human resources management, 10, pp. 31-72. Greenwich, CT: JAI Press.

Judge, T.A., Locke, E.A., Durhan, C. \& Kluger, A.N. (1998). Dispositional effects on job and life satisfaction: The role of core evaluations. Journal of Applied Psychology, 83, 119-133.

Judge, T.A., Higins, C.A., Thoresen, C.J. \& Barrick, M.R. (1999). The Big Five personality traits and career success across the life span. Personnel Psychology, 52, 621-652.

Kaiser, H.F. (1970). A second-generation Little Jiffy. Psychometrika, 35, 401-415.

Lawrence, P.R. \& Lorsch, J.W. (1967). Organization and Environment: Managing differentiation and integration. Cambridge, MA: Division of Research, Graduate School of Business Administration, Harvard University.

Levert, T., Lucas, M. \& Ortlepp, K. (2000). Burnout in psychiatric nurses: Contributions of the work environment and a sense of coherence. South African Journal of Psychology, $30,36-44$

Miller, R.L., Griffin, M.A., Hart, P. \& Hart, P.M. (1999). Personality and organizational health: the role of conscientiousness. Work \& Stress, 1. Retrieved March 4, 2003 from World Wide Web: http://0 web3.epnet.com.raulib.rau.ac.za

Nadler, D.A. \& Tushman, M.L. (1986). A model for diagnosing organizational behaviour. In T.C. Head (ed.) Organizational Behavior: Cases, Exercises, and Readings. Boston, MA: Houghton Mifflin Company.

Organ, D.W. \& Lingl, A. (1995). Personality, satisfaction, and organisational citizenship behavior. Journal of Social Psychology, 135, 31-59.

Payne, R. \& Pugh, D.S. (1983). Organizational structure and climate. In M.D. Dunnette (ed.) Handbook of Industrial and Organizational Psychology. New York: John Wiley \& Sons. 
Rothman, S. \& Coetzer, E.P. (2002). The relationship between personality dimensions and job satisfaction. Business Dynamics, 11, 29-42.

Sand, A. (2003). Nurses' personalities, nursing-related qualities and work satisfaction: a 10 year perspective. Journal of Clinical Nursing, 12, 177-188.

Schepers, J.M. (1992). Toetskonstruksie: Teorie en Praktyk. [Test Construction: Theory and Practice], Johannesburg: RAU pers.

Sempane, M.E., Rieger, H.S. \& Roodt, G. (2002). Job satisfaction in relation to organizational culture. SA Journal of Industrial Psychology, 28, 23-30.

Sherer, M., Maddux, J.E., Mercandante, B., Prentice-Dunn, S., Jacobs, B. \& Rogers, R.W. (1982). The Self-Efficacy Scale: Construction and Validation. Psychological Reports, 51, 663671.

Seibert, S.E. \& Kraimer, M.L. (2001). The Five-Factor Model of Personality and Career Success. Journal of Vocational Behavior, 58, 1-20.

Staw, B. \& Ross, J. (1985). Stability in the midst of change: A dispositional approach to job attitudes. Journal of Applied Psychology, 70, 469-480.

Strümpfer, D.J.W., \& Mlonzi, E.N. (2001). Antonovksy's Sense of Coherence scale and job attitudes: Three studies. South African Journal of Psychology, 31, 30-38.

Sullivan-Havens, D. \& Aiken, L.H. (1999). Shaping systems to promote desired outcomes: The magnet hospital. Journal of Nursing Administration, 29, 14-19.
Tokar, D. \& Subich, L. (1997). Relative contribution of congruence and personality dimensions to job satisfaction. Journal of Vocational Behaviour, 50, 482-491.

Tellegen, A. (1985). Structures of mood and personality and their relevance to assessing anxiety, with an emphasis on self-report. In A.H. Tuma \& J.D. Maser (Eds.) Anxiety and the anxiety disorders. Hillsdale. NJ: Erlbaum.

Thompson,J.L. (2001). Strategic Management. Fourth Edition. Tompson Learning: United States.

Tuma, A.H. \& Maser, J.D. (Eds.) (1985). Anxiety and the anxiety disorders. Hillsdale, NJ: Erlbaum

Turban, D.B. \& Dougherty, T.W. (1994). Role of protégé personality in receipt of mentoring and career success. Academy of Management Journal, 37, 688-702.

Turner, J.H., Filley, A.C. \& House, R.J. (eds.) (1972). Studies in Managerial Process and Organizational Behavior. Glenview, ILL: Scott, Foresman \& Company.

Tzeng, H., Ketefian, S. \& Redman, R.W. (2002). Relationship of nurses' assessment of organisational culture, job satisfaction, and patient satisfaction with nursing care. International Journal of Nursing Studies, 39, 79-84.

Van der Post, W.Z., de Coning, T.J. \& Smith, E.v.d.M. (1997). An instrument to measure organisational culture. South African Journal of Business Management, 28 (4), 147-168.

Weiss, D.J., Dawes, R.V., England, G.W. \& Lofquist, LH. (1967). Manual for the Minnesota Satisfaction Questionnaire. Minneapolis: University of Minnesota. 